\title{
A Psychometric Investigation into the Structure of Deception Strategy Use
}

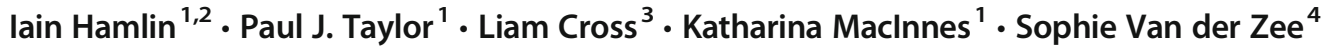 \\ Published online: 26 March 2020 \\ (C) The Author(s) 2020
}

\begin{abstract}
This paper uses a data-driven approach to identify the psychological factors that underlie the array of strategies that people use to hide their deceit. Two hundred and nine participants told two lies and two truths and then completed a self-report scale that elicited their experiences when deceiving. A factor analysis of responses produced four factors, three of which were strategic in nature: Nonverbal behaviour control, which relates to attempts to monitor and control nonverbal behaviour when lying; Detail, which relates to attempts to produce detailed, engaging lies; Cognitive difficulty, which relates to the cognitive difficulties experienced when lying and their strategic consequences; and Anxiety, which relates to the negative emotions experienced when deceiving. The results further our understanding of the psychological processes that underpin deception and suggest several potentially fruitful avenues for future research.
\end{abstract}

Keywords Deception · Deception strategies · Behaviour control

In order to improve our ability to detect deception, there is a need to gain a better understanding of valid deception cues and their origins. An important part of recent attempts to understand the origins of cues to deception is the study of deception strategies. It has long been thought that cues to deception can emerge from liars' strategic attempts to appear honest (Ekman and Friesen 1969; Knapp et al. 1974; Mehrabian

Iain Hamlin

i.hamlin@derby.ac.uk

Paul J. Taylor

p.j.taylor@lancs.ac.uk

Liam Cross

liam.cross@edgehill.ac.uk

Katharina MacInnes

katharinamacinnes@googlemail.com

Sophie Van der Zee

s.c.vander.zee@vu.nl

1 Department of Psychology, Lancaster University, Lancaster, UK

2 UDOL, University of Derby, Enterprise Centre, Bridge Street, Derby DE1 3LD, UK

3 Department of Psychology, Edge Hill University, Ormskirk, UK

4 Department of Experimental and Applied Psychology, Vrije Universiteit, Amsterdam, Netherlands
1971; Sporer and Schwandt 2006, 2007; Zuckerman et al. 1981). For example, Vrij et al. (1996) found that participants' self-reports of the extent to which they strategically controlled their behaviour when lying were associated with a measured decrease in their subtle movements during deception. Improving our understanding of deception strategies is thus a promising avenue for better understanding deception cues and, by extension, improving accuracy in deception detection (Granhag and Hartwig 2008).

Deception strategies have been central to deception theory since the beginning of modern deception research. One of the earliest descriptions of behaviour control strategies and their impact on cues to deception was put forward by Ekman and Friesen (1969). When outlining their theory, Ekman and Friesen made a distinction between 'inhibition' and 'simulation' strategies. Inhibition refers to attempts by the deceiver to omit information from their deceptive message to avoid 'leakage' of information that they want to keep hidden. In contrast, simulation refers to attempts to generate the deceptive content of messages to create an impression of truthfulness. This can be as simple as filling the holes in a deceptive message left by an inhibition strategy or as complicated as creating and maintaining complex deceptive behaviour, simulating the emotions and generating the verbal content that the liar believes approximates the behaviour of a truth-teller.

Knapp et al. (1974) mirrored Ekman and Friesen's (1969) two-factor model of behaviour control strategies and made 
further suggestions as to how these strategies might manifest in behaviour. In particular, they hypothesised that, in an attempt to appear honest by adopting behaviours that they assume are associated with truthfulness, liars might overshoot the mark and produce a set of exaggerated behaviours which represent a caricature of a truthful pattern of behaviour. For example, compensating for fears that they might reduce eye contact when lying, liars might make even more eye contact than might somebody who was telling the truth. This category of deception cues maps well onto those that Ekman and Friesen predict would result from the adoption of a simulation strategy.

In the modern literature, the possibility that liars adopt simulation strategies is usually at best given only brief acknowledgement. Deception strategies are instead mainly equated with attempts to reduce behaviour so as to inhibit the production of cues to deception (e.g. Burgoon and Buller 1994; DePaulo et al. 2003; Sporer and Schwandt 2006, 2007; Vrij 2010; Vrij et al. 1996). This is perhaps because deception strategies are usually inferred from behaviour, and several influential meta-analyses of deception cues revealed mainly decreases rather than increases in behaviour when lying, providing evidence for 'inhibition' strategies rather than simulation strategies (DePaulo et al. 2003; Sporer and Schwandt 2007).

Little direct measurement of strategies took place until relatively recently, when a significant amount of research effort investigated self-reported deception strategies. Recent, datadriven research on self-reported deception strategies typically involves participants taking part in a deception task before describing, in response to an open-ended question, the strategies they employed when lying. These self-reported strategies are then content analysed into superordinate categories representing conceptually related clusters of strategies. The strategies identified by this approach are numerous and diverse, reflecting the many ways people control their verbal content and nonverbal behaviour. Colwell et al. (2006) produced a list of 14 categories into which participants' selfreported deception strategies were placed by coders, including appearing coherent and consistent and maintaining a calm tone of voice. Other have reported strategies such as remaining calm, avoiding incriminating details, appearing pleasant (Hartwig et al. 2007), maintaining eye contact, avoiding hesitations (Strömwall et al. 2006), telling an uncomplicated story (Masip 2013) providing rich details, laughing and joking, behaving consistently between truths and lies, and believing one's own lies (Strömwall and Willén 2011).

It remains unclear, however, how these myriad strategies are related to one another. Most research simply categorises participants' self-reported strategies via conceptual similarity (as judged by research volunteers), rather than by investigating how they actually co-vary with one another. Consequently, these categories may not reflect the true nature of the interrelationships among strategies as they occur when a person is lying. The exact nature of these strategies, the constellations they form with other strategies, and the psychological factors that underpin them have yet to be established.

As well as improving our understanding of the interrelationships among strategies, the present research also addresses another obstacle to deception detection success: individual differences in behaviour when deceiving. One of the reasons why deception cues are generally weak and inconsistent is because different people lie in different ways (Vrij 2010). For example, in a reanalysis of data from three studies on hand movements in deception, Vrij et al. (1997) reported that whereas $52 \%$ of participants decreased hand movements when lying, $48 \%$ of participants either increased their hand movements or demonstrated no difference in the number of hand movements between truths and lies. If deception detection proceeds on the basis of general rules, such as that deception is generally associated with a decrease in body movement, then such inter-individual variation in behavioural cues necessarily has a negative impact on deception detection accuracy. However, if individual differences are taken into account - that is, if the variation in cues to deception between liars is understood and this understanding is integrated into veracity judgments - then deception detection rates should improve. Previous attempts to understand individual differences in cues to deception have produced mixed results (Vrij 2010). Deception strategies represent a potentially important source of individual differences in cues to deception. Understanding the structure of individual differences in strategy use is an important step towards a better understanding of individual differences in cues to deception and, by extension, higher levels of accuracy when judging veracity.

The present research examines the structure of selfreported deception strategies. It does so by generating a questionnaire-based measure from free reports of deception phenomenology, and by using this measure to collect data on what liars' experience when they lie. These data are then subjected to a factor analysis to identify the latent constructs underpinning these experiences. This approach extends the current literature in several ways. The methodology mirrors that of previous research, but instead of subjectively categorising strategies, we statistically examine how different strategies co-vary. This should give a more accurate insight into psychological (rather than purely semantic) interrelationships between strategies than content analysis. Also, previous strategies research has been criticised over the possible effect on the content of self-reports of the instructions regarding what aspects of strategies to report (Strömwall and Willén 2011). The current study attempts to minimise the influence of instructions on self-reports of strategy use by examining everything participants report thinking and feeling when lying, not just reports of strategies. 
Although this study is largely exploratory in nature, we have several hypotheses as to the nature of the results. First, we hypothesise that strategy use will be multidimensional in nature. Behaviour control is often operationalised in the literature as a single factor representing decreases in behaviour, and, because very few strategies are necessarily mutually exclusive, it is indeed possible that it is a unidimensional construct (e.g. a global factor of strategy effort). However, the nature of self-reported strategies is so diverse that it seems likely that behaviour control is multidimensional in nature. Second, we hypothesise that the actual structure of deception strategies is not as complex as the categorisations produced in previous deception strategy research (strategies studies commonly induce over 10 strategy categories). The content of the different strategy categories reported in the literature is often conceptually related, so it is likely that a small number of broad strategy dimensions underpin strategy use. Third, in line with previous research on deception strategies, we hypothesise that the content of the main dimensions of strategy use will reflect two main forms of regulation: purposeful control of nonverbal cues and regulation and manipulation of speech content to produce plausible lies (Hartwig et al. 2010; Strömwall and Willén 2011).

\section{Method}

\section{Participants}

Participants were 209 undergraduate students (71 males) who volunteered to participate for either $£ 5$ or course credit. Their average age was 20.4 years $(\mathrm{SD}=2.59)$.

\section{Materials}

Post-session 'Deception Phenomenology' Questionnaire A questionnaire was created to measure participants' experiences when lying. The items in this questionnaire were extracted from the written responses of 81 participants in two previous deception experiments to the post-session request: 'Please write at least a paragraph about what was going on in your mind when you were lying.' These two previous experiments involved participants undertaking a small number of lab-based activities before lying to an interviewer and claiming that they had in fact taken part in several other activities as well. We asked participants to write down everything that went on in their minds when they were lying. A broad request such as this should be expected to mitigate the concerns raised previously that the exact instructions given in previous strategy research appear to encourage participants to focus on and report specific types of deception strategy (Strömwall and Willén 2011). This list of items was compiled into a deception phenomenology questionnaire. All items generated by participants in the pilot were used in the questionnaire after repetitions and ambiguous items were removed and after some items were altered to become grammatical, leaving 102 items for use in the experiment. Participants were instructed to 'rate how frequently you experienced the following mental phenomena when lying during the interview', with each item rated on 5-point scale from Never (1) to Very Frequently (5).

\section{Procedure}

On giving informed consent, participants were taken to a table in a nearby room where they were presented with a collection of props that would allow them to take part in four different activities. The activities were (i) a bird identification activity in which participants were given a photograph of a North American bird (randomly chosen from a pool of 150 photographs) and asked to use a bird identification field guide to identify the bird to species level; (ii) a paper plane making activity requiring participants to make a simple paper plane by following an instructional, laptop-based video clip; (iii) a picture drawing activity requiring participants to spend two minutes drawing a picture about a set topic randomly chosen from a pool of 100 topics; and (iv) a video activity that comprised watching a short YouTube video clip on a laptop randomly chosen from a pool of 100 . These activities were picked to capture a reasonably broad spectrum of passive and active everyday solitary activities of varying emotional content.

Participants were told that they should undertake just two out of these four activities, as dictated by their instruction sheet. The assignment of activities varied randomly both across participants and between veracity conditions. They were told that, on completing the tasks, they would go to another room to be interviewed about their experiences. At interview, they were required to tell the interviewer the truth about the two activities they completed and also to lie and pretend that they had completed the other two activities. All participants thus told two lies and two truths. The interviewer asked each participant five questions. The first question about each activity was a general one ('Tell me everything you remember doing during the activity') and the remaining four, more specific questions were asked in random order. The four specific questions varied according to the activity. The interviewer was blind to whether the participant was lying or telling the truth, but knew that the participant would tell two lies and two truths. At the end of the session, participants completed the post-session questionnaire. 


\section{Results}

\section{Structure of Deception Phenomenology}

Participants' questionnaire responses were submitted to a factor analysis to draw out the dimensions that underpin their experiences of lying. Although factor analysis is usually regarded as requiring large sample sizes in order to produce reliable results, claims regarding requisite sample sizes vary markedly and are often based on little other than the personal experience of the proponent (MacCallum et al. 2001; MacCallum et al. 1999). The few empirical studies that have investigated the effect of sample size on factor recovery suggest that there is no absolute sample size or item to participant ratio that is sufficient to recover a set of population factors (De Winter et al. 2009; MacCallum et al. 1999, 2001; Mundfrom et al. 2005). This empirical research suggests that the most important factor influencing the accurate recovery of population factors is the ratio of variables to factors. If each factor is defined by at least 6 or 7 highly loading items, then the factor solution is almost always robust, even with sample sizes of 100-200 (MacCallum et al. 2001). This remains the case even with low communalities (MacCallum et al. 1999; Mundfrom et al. 2005). Because the content of the different strategy categories reported in the literature is often conceptually related, we anticipated that the questionnaire items would be split between a small number of consequently overdetermined factors, resulting in a factor structure robust enough to be recovered with a sample size of 209.

To assess whether or not the data were suitable for this approach, Bartlett's test of sphericity was performed on the correlation matrix formed by the phenomenology data and the Kaiser-Meyer-Olkin (KMO) measure of sampling adequacy was calculated. Bartlett's test of sphericity was significant, $\chi 2(5151)=13,103.02, p<.001$, and Kaiser's measure of sampling adequacy was 0.78 (values of 0.5 or above generally being held to be suitable for factor analysis; Hair et al. 1995; Tabachnick and Fidell 2001). Both tests therefore suggested that, in line with our first hypothesis, the data were dimensional in nature and suitable for factor analysis.

To investigate the main dimensions of experiences during deception, an Unweighted Least Squares (ULS) factor analysis was performed with Oblimin rotation. A polychoric correlation matrix was analysed because the data were ordinal in nature, and Pearson correlations have been found to underestimate the strength of relationships between ordinal variables (Olsson 1979). We used an Oblimin rotation, a form of oblique rotation, because there was no theoretical reason to assume that the factors would be uncorrelated.

To inform the decision as to how many factors to extract, we conducted three statistical analyses. A parallel analysis (Timmerman and Lorenzo-Seva 2011) suggested that 7 factors should be extracted. However, when applied to datasets with sample sizes well over 100 and large item to factor ratios, parallel analysis often errs towards the over-extraction of factors (Lorenzo-Seva et al. 2011). Two alternative statistical methods for selecting the number of common factors, reported to be more reliable under these conditions, are the Hull method (Lorenzo-Seva et al. 2011) and the Minimum Average Partial (MAP) test (Velicer 1976). The Hull method seeks to identify the number of factors which represents the best balance between goodness-of-fit and the degrees of freedom. This method suggested a two-factor solution was most appropriate. The MAP test suggested a five-factor solution. Additionally, a subjective examination of eigenvalues suggested that a four-factor solution was appropriate (the first nine eigenvalues were $15.22,14.03,6.12,4.27,2.99,2.77$, $2.48,2.31$, and 2.12 respectively).

We then undertook a subjective examination of the factor loadings. Specifically, an examination of factor loadings in 2 , $3,4,5,6$, and 7 factor solutions suggested a four-factor solution was most appropriate. The two-factor solution comprised an emotional-cognitive difficulty factor and a very broad behaviour control factor. When 3 factors were extracted, the behaviour control factor split into two readily interpretable factors, one pertaining to nonverbal behaviour control, the other pertaining to attempts to create convincing lie content. The extraction of a four-factor solution produced an additional factor with high loadings from items pertaining to cognitive difficulty. No further psychologically and psychometrically valid factors were produced by extracting larger factor solutions. The extraction of a five-factor solution produced an additional factor which appeared only to represent a 'bloated specific' (Cattell and Tsujioka 1964) - that is, a factor composed mainly of similarly-worded items. The items pertained to difficulty maintaining eye contact (e.g. 'I found it difficult to keep eye contact', 'I was conscious of the fact I kept losing eye contact', 'I could not look at the person I was lying to', 'I tried to avoid looking at the person I was lying to'). A six-factor solution produced an additional bloated specific with high loading items pertaining to the linking of deceptive narratives to previous experiences (e.g. 'I attempted to link my lie to things I had experienced before', 'I linked the content of my lie to my own real-life experiences in order to make it more believable', 'I drew on my previous experiences in real life when constructing my lie'). Finally, the additional factor produced by a seven-factor solution was very small and had no large factor loadings (i.e. loadings above 0.5 ). Consequently, and in line with our second hypothesis that the structure of deception strategy use would be characterised by a small number of dimensions, a four-factor solution was adopted, which accounted for $38.9 \%$ of the variance in the correlation matrix.

Table 1 presents the item loadings from the four-factor model. To aid interpretation, only item loadings of 0.4 or higher are displayed. 
Table 1 Factor loadings of the questionnaire items on four factors

Questionnaire factor

Questionnaire item

Cognitive Nonverbal Behaviour Anxiety Detail
Difficulty Control

I tried to plead ignorance to ease the pressure of having to make up a lie

0.58
0.53
-0.51
0.50
0.49
0.48
0.48
0.48
0.44
-0.43
0.42
0.42
0.41

I was consciously trying to control the speed of my speech

0.58

I tried to make what I was saying as realistic as possible

0.50

I said things during my lie which were designed to avoid further questions being asked

0.49

I tried to say that I could not remember specific details

0.48

I tried to keep a monotone voice

0.48

My mind wandered, resulting in uneasy pauses

0.48

0.44

I felt confused

0.43

0.42

I tried not to smile or laugh when lying

0.42

I could feel my body shaking

0.41

I tried to keep my body position the same as it was when I was being honest

I thought about the amount of eye contact I was making with the person I was lying to

I tried not to change anything I was doing physically from when I was telling the truth

I tried to match the style of my lies to the style of my truthful utterances

I attempted to communicate information in the same manner when lying as when telling the truth

I was conscious of my body language

I tried to talk at a steady speed

I tried to maintain eye contact with the person I was lying to

I tried to control any 'nervous' actions

I tried to be calm

I tried to avoid using any body language that would indicate that I was lying

I tried to behave the same way as when I was telling the truth

I tried not to look particularly nervous

I tried to keep my body language consistent between my lies and truths

I tried to look calm

I tried to make sure that I did not contradict myself

I tried to keep still

I tried to bear in mind the signs that people give off when lying

I kept my body movements to a minimum

I tried to match the length of my deceptive responses to the length of my truthful ones

I tried to control the direction my eyes were looking

I tried to remain as natural as possible

I was so focused on what I was saying, I lost track of my body movements

I thought it was obvious I was lying

I felt anxious

I worried I would be found out

I found lying scary

I did not feel any different when lying as compared to telling the truth

I felt that my hesitations gave me away 
Table 1 (continued)

Questionnaire factor

\begin{tabular}{lll}
\cline { 2 - 2 } Questionnaire item & $\begin{array}{l}\text { Cognitive } \\
\text { Difficulty }\end{array}$ & $\begin{array}{l}\text { Nonverbal Behaviour Anxiety Detail } \\
\text { Control }\end{array}$ \\
\hline
\end{tabular}

I found it hard to think quickly

I did not like lying

0.6

I stumbled with what I was sayin

0.6

I found it hard to invent the details of my lie $\quad 0.57$

I hoped I would not be questioned any further 0.56

I found it difficult to keep eye contact 0.56

The more I tried to elaborate on my lie the more I felt it was obvious I was lying 0.55

My heartbeat increased 0.55

I was aware that the detail in my lie was poor compared to the detail in my truthful 0.54

statements

I was conscious of the fact that I kept hesitating 0.53

I felt guilty 0.52

Sometimes I could not think of anything to say 0.5

My speech became faster 0.46

I could not look at the person I was lying to 0.46

I made relatively long pauses because I had to create a lie $\quad 0.44$

I found it difficult to keep track of my body movements when lying $\quad 0.41$

I found it hard to picture my lie in my head 0.41

I tried to make my lie sound natural by adding emotion $\quad 0.67$

I imagined myself actually experiencing what I was lying about $\quad 0.62$

I attempted to link my lie to things I had experienced before 0.62

I linked the content of my lie to my own real life experiences in order to make it more 0.62 believable

I drew on my previous experiences in real life when constructing my lie $\quad 0.59$

As my lie progressed I became more creative 0.57

I tried to be humorous in order to distract the person I was lying to from paying attention to 0.56 my body language
tried to be expressive

I tried to make up extra little details to make my lie more convincing 0.54

I tried to decorate my story with a few irrelevancies 0.52

I tried to imagine that the thing I was lying about was actually true 0.52

I made my lies seem natural by adding detail $\quad 0.47$

I tried to think that I was telling a story rather than lying 0.46

I tried to give as much detail as possible in order to sound convincing 0.46

I repeated elements of my lie in an attempt to make my lie more realistic 0.46

I tried to think of details which would make my lie believable 0.44

I tried to think up answers as quickly as I could in order to sound convincing 0.41

I attempted to appear confident so that I would come across as believable 0.4

Factor loadings below .4 are not displayed

Factor 1, Cognitive difficulty, represents the cognitive difficulty experienced by participants when producing their lies (e.g. 'My mind wandered, resulting in uneasy pauses' and 'I found it hard to keep the content of my lie consistent') and behavioural efforts to minimize the impact of this difficulty (e.g. 'I tried to say that I could not remember specific details' and 'I plead ignorance to ease the pressure of having to make up a lie').

Factor 2, Nonverbal behaviour control, represents deliberate attempts by participants to monitor and control their nonverbal behaviour when lying. Nonverbal behaviour control is a relatively low-level strategy involving the moderation of specific behaviours such as eye contact 
(i.e. 'I tried to maintain eye contact with the person I was lying to'), speed of speech (i.e. 'I was consciously trying to control the speed of my speech') and tone of voice (i.e. 'I tried to keep a monotone voice'). Frequently, this attempted moderation takes the form of suppressing behaviours, such as body movements, fast rate of speech and other nervous behaviours, which many laypeople assume are cues to deception (Hartwig and Bond 2011). Also, central to this factor are attempts to maintain consistency in behaviour between truths and lies (e.g. 'I tried to keep my body language consistent between my truths and lies.').

Factor 3, Anxiety, relates to one of the unintended phenomenological consequences of lying, namely the experience of negative emotion (e.g. 'I found lying scary' and 'I felt anxious'). Only items related to negative emotion loaded on this factor: no items which obviously described the positive emotions associated with duping delight were associated with this dimension. Additionally, this factor contained several items related to the level of confidence one has in one's lies (e.g. 'I felt unconvincing'). Unlike the other three factors extracted, Anxiety does not appear to be strategic in nature.

Factor 4, Detail, reflects strategic attempts to appear truthful by increasing the amount of detail, humour, and emotion contained in one's responses. Central to this dimension is the high-level deception strategy of drawing on previous, real-life experiences to make the content of lies sound more authentic (e.g. 'I linked the content of my lie to my own real-life experiences in order to make it more believable'). Participants scoring highly on this dimension also tended to report attempting to directly control verbal behaviours by, for example, making their lies detailed (e.g. 'I made my lies seem natural by adding detail'), adding extra emotion into their accounts (e.g. 'I tried to make my lie sound natural by adding emotion') and utilising humour (e.g. 'I tried to be humorous in order to distract the person I was lying to from paying attention to my body language').

There were moderate correlations among the four identified factors. Table 2 presents an inter-factor correlation matrix. The largest correlations were between Cognitive difficulty and Anxiety and between Detail and Nonverbal behaviour control.

Table 2 Inter-factor correlation matrix

\begin{tabular}{lllll}
\hline Factors & 1 & 2 & 3 & 4 \\
\hline 1. Cognitive difficulty & - & & & \\
2. Nonverbal behaviour control & -0.02 & - & & \\
3. Anxiety & 0.25 & 0.03 & - & \\
4. Detail & -0.15 & 0.3 & 0.01 & - \\
\hline
\end{tabular}

\section{Discussion}

Using a bottom-up approach, the current study derived three factors of deception strategy use in a lab-based deception task. In doing so the study clarified the superordinate factor structure that organizes the numerous deception strategies that have been reported in the literature. As hypothesised, strategy use was multidimensional and defined by a small number of broad factors: a factor analysis of participants' scores on a postsession deception phenomenology questionnaire recovered four phenomenology factors, three of which represented deception strategies.

Deception strategy use was multidimensional, being defined by three large factors. As hypothesised, the content of the factors represented the purposeful control of nonverbal cues and manipulation of speech content to produce plausible lies. Indeed, one factor essentially represented the control of nonverbal cues and another the manipulation of speech content. The factors that emerged from our analysis also fit well with the broader deception research literature. For example, the Cognitive difficulty factor maps on to the construct of cognitive load, which has occupied a central position in deception theory for several decades (Greene et al. 1985; Miller and Stiff 1993; Sporer and Schwandt 2006; Vrij et al. 2008; Zuckerman et al. 1981). Although the factor was defined mainly by items pertaining to the experience of cognitive load, it was also defined by items describing deliberate efforts to account for such difficulties. The strategic element was relatively small and focussed on attempts to say as little as possible, for example by claiming a lapse of memory.

Similarly, the Nonverbal behaviour control factor reported here fits well with the modern conception of behaviour control in the research literature (e.g. Sporer and Schwandt 2007; Zuckerman et al. 1981). Behaviour control is generally considered to focus on attempts to suppress the increases in behaviours thought by most people to index deception. In the present study, the factor was defined by items such as 'I tried to control any nervous actions', 'I tried to keep still', and 'I tried maintain eye contact with the person I was lying to'. The emergence of this factor in the present research mirrors the results of previous deception strategy research (Hartwig et al. 2007; Masip 2013; Strömwall et al. 2006; Strömwall and Willén 2011) and supports the central position of this type of behaviour control strategy in deception theory.

Perhaps the most interesting factor to emerge from the study was the strategy dimension, 'Detail'. The emergence of this factor is in line with several previous studies which have reported that producing detailed lies is one of the main deception strategies reported by lairs (Hartwig et al. 2007; Strömwall et al. 2006; Strömwall and Willén 2011). This factor differed from the preceding in several ways. First, it appeared to be mainly verbal in nature, focussing on the fluent 
and confident delivery of a detailed deceptive message. Second, whereas some of the content of the Nonverbal behaviour control factor related to attempts to suppress behaviour, many of the items with high loadings on the Detail factor pertained to attempts to increase behaviour, in the form of adding extra details to deceptive messages.

Another important difference between these two behaviour control dimensions was the latter's mix of both strategies that directly control behaviour and indirectly control behaviour. Whereas all the items loading highly on the Nonverbal behaviour control factor described direct attempts to control specific behaviours such as gaze, facial expression and speed of speech, the Detail factor was defined by several items pertaining to the strategy of indirectly influencing behaviour by utilising previous experiences in the construction of lies. The importance of this strategy has been highlighted by recent research. In a study on self-reported deception strategies, Leins et al. (2013) found that reporting previous experiences was the most widespread deception strategy used by participants. The results of the present research provide further support for the importance of this strategy. Another, similar strategy contained within the Detail factor was self-deception. Participants attempted to make their lies more naturalistic by convincing themselves that what they were lying about was actually true. This finding is in line with modern theories of self-deception, which suggest that one of the reasons selfdeception evolved was to produce more convincing lies in the face of ever more proficient human lie detectors (von Hippel and Trivers 2011). The Detail factor represents a type of behaviour control strategy that has been relatively neglected in the deception literature and should be the focus of further research attention.

Interestingly, the latter two strategy factors were correlated. People who attempted to control their nonverbal behaviour also tended to try to add detail and expressiveness to their deceptive accounts. Indeed, the relatively large values of the first two eigenvalues of the reduced correlation matrix suggested that a two-factor solution might best represent the structure of the data, with one of the factors representing a general 'behaviour control' factor. However, there is a significant pragmatic benefit to adopting a multidimensional rather than unidimensional representation of deception strategies. The different strategy factors might be expected to have very different effects on nonverbal cues to deception: adding extra details should result in an increase in nonverbal behaviour, for example through increased gesture production, whereas increased nonverbal behaviour control should result in a decrease in nonverbal behaviour. Consequently, the content of a single strategy superfactor would be heterogeneous in terms of the effects it has on cues to deception, making it of limited value in an applied context.
The fourth factor, Anxiety, was not strategic in nature. It represented the negative emotions experienced when lying. Furthermore, the pattern of correlations between this factor and the strategy factors suggests that anxiety does not strongly impact on strategic behaviour when deceiving. Its emergence is almost certainly a result of the breadth of request given to the participants who generated the questionnaire items: they were asked to report all aspects of deception phenomenology, not just strategies. However, the emergence of this factor should be of interest to deception researchers. The positive correlation between the Anxiety and Cognitive Difficulty factors serves as a reminder that these two phenomena co-occur in a deception context. Anxiety directs cognitive resources away from executive processes and towards the perception of threatening stimuli (McNaughton and Corr 2008; Vytal et al. 2012). In the context of deception, increased anxiety when lying would be expected to reduce the cognitive resources that participants are able to direct towards the task of creating a lie. Conversely, it is also feasible that experiencing cognitive difficulty when creating lies could have been a source of anxiety for liars, further strengthening the connection between these two constructs in the present research (Vrij and Granhag 2012).

The results of the present study may help inform attempts to improve deception detection performance in at least three ways. First, the efficacy of veracity judgments based on clusters of cues may be a function of how well those cues cover the four different experience dimensions reported by participants. When the coverage is reduced to one or two of the identified dimensions then we would predict lower accuracy in veracity judgements than when all four dimensions were represented.

Second, the factors identified in this study suggest different ways in which interview tactics can make lying more difficult. To date, most research has focused on developing methods for increasing cognitive difficulty, yet the explication of the different dimensions suggests other foci may be possible. For example, it might be possible to increase the magnitude of cues to deception stemming from the nonverbal behaviour control strategy by increasing the salience of the extent to which liars have their body movements observed. Such a perceived increase in scrutiny should, providing there is differential use of the strategy between liars and truth-tellers, amplify cues to deception arising from the controlled suppression of body movements.

Third, the factors reported in the current study might help to improve deception detection by defining new individual differences variables for investigation in the context of deception. Indeed, compared with personality traits, the factors reported here would be expected to have a direct influence on the production of cues to deception, so an argument can be 
made that this is the best level at which to understand and investigate individual differences in deception cues. To further investigate the suitability of the four factors as individual differences variables, future research should examine the stability of liars' standing on the factors across deceptive situations.

Several limitations of the present research are worth noting. First, it is worth highlighting the reliance of this study on selfreports. Humans can be limited in their capacity to accurately self-report on their behaviours (Fiske and Taylor 2008; Nisbett and Ross 1980; Nisbett and Wilson 1977). However, selfreports are almost certainly a more valid way of measuring explicit deception strategies than behavioural observation. It would be difficult to imagine how a researcher could accurately infer the use of a strategy such as 'I imagined myself actually experiencing what I was lying about' or 'I attempted to link my lies to things I had experienced before' by objectively measuring behaviour. Consequently, self-report methodology forms the backbone of modern research on deception strategies (e.g. Clemens et al. 2013; Colwell et al. 2006; Hartwig et al. 2007; Leins et al. 2013; Masip 2013; Strömwall et al. 2006; Strömwall and Willén 2011; Vrij et al. 2010). Even one of the most famous critiques of the self-report method suggests that the data produced from self-reports are more valid than information from external observations when it comes to 'emotions, evaluations, and plans' (Nisbett and Wilson 1977, p. 255). Indeed, in the context of deception strategies, previous reports of significant correlations between self-reports of behaviour control and behaviour when lying (Vrij et al. 1996) suggest that self-reports of deception strategies possess at least some validity. It remains possible though that parallel, unconscious strategies are at play in deceivers' minds which are unavailable to introspection, and so not directly measurable by self-report.

Second, it remains unclear whether the factors reported will generalize across different types of lie, including those in applied forensic contexts, where lies would be expected to be more self-motivated and include denials of having done something. Such lies stand in contrast to those produced in the present study, where liars simply claimed to have done something that they had not. This is an empirical question and future research should investigate the replicability of the deception factors across different types of lie. However, the factors are relatively broad in terms of content and are consequently of relevance to many deceptive situations, so it is expected that they will demonstrate a high degree of replicability across deception contexts. Furthermore, research on offenders' self-reported deception strategies suggests that the strategies used by prisoners in interrogations overlap significantly with those of students taking part in lab-based deception studies (Strömwall and Willén 2011). However, it is obvious that a different set of factors will underpin lies perpetrated in other modalities, for example in online communication, where nonverbal behaviour is often irrelevant. Future research should establish how stable the three strategy factors reported here are across deception type, context and modality.

Third, the present research examined only deception strategies; it did not investigate the strategies employed by truthtellers. It is possible that one or more of the three broad deception strategy factors reported here also represents one of the main factors organising the strategies of truth-tellers during interviews. Future research should investigate whether such a potential overlap exists between liars' and truth-tellers' strategy factors. Cues to deception would be expected to be most pronounced when they relate to factors where there is no counterpart in truth-tellers. However, it should be noted that even an overlap between truth-tellers' and liars' strategies could produce cues to deception if liars' behaviour is affected by that strategy factor more (or less) strongly than truthtellers'.

Fourth, most factor analyses account for a greater percentage of variance in the data than the factor analysis conducted as part of the present research. The four factors extracted accounted for $38.9 \%$ of the variance in scores on the deception phenomenology questionnaire. In a meta-analysis of the amount of variance accounted for in factor analysis, Peterson (2000) reported that factor analyses with 31 or more items on average accounted for $48.1 \%$ of the variance in the correlation matrix. In contrast to most factor analyses, our data were not pre-structured to increase the value of the loadings on the resultant factors, and, by extension, increase the amount of variance accounted for by the factor solution. Moreover, our factor analysis was conducted on a relatively large number of items (102) and the greater the number of items in a factor analysis, the less variance any given number of factors will account for (Peterson 2000). For both of these statistical reasons, it should be expected that the present factor analysis would produce a solution which accounts for less variance than most.

\section{Conclusion}

Using a data-driven, factor analytic approach, this study reported three broad factors representing the main strategies participants used when lying. One factor, pertaining to strategic attempts to control nonverbal behaviour, mapped onto the way behaviour control is usually conceptualised in the deception literature. A second factor mapped onto the construct of cognitive load, representing the cognitive difficulty experienced when lying and the strategic behaviours produced to cope with it. A third factor, defined by attempts to increase the detail, emotion, and humour in lies, was particularly noteworthy and represents a construct in deception research especially worthy of further investigation. 


\section{Compliance with Ethical Standards}

Conflict of Interest The authors declare that they have no conflict of interest.

Ethical Approval All procedures performed in studies involving human participants were in accordance with the ethical standards of the Lancaster University Psychology Department ethics committee and with the 1964 Helsinki declaration and its later amendments or comparable ethical standards.

Informed Consent Informed consent was obtained from all individual participants included in the study.

Open Access This article is licensed under a Creative Commons Attribution 4.0 International License, which permits use, sharing, adaptation, distribution and reproduction in any medium or format, as long as you give appropriate credit to the original author(s) and the source, provide a link to the Creative Commons licence, and indicate if changes were made. The images or other third party material in this article are included in the article's Creative Commons licence, unless indicated otherwise in a credit line to the material. If material is not included in the article's Creative Commons licence and your intended use is not permitted by statutory regulation or exceeds the permitted use, you will need to obtain permission directly from the copyright holder. To view a copy of this licence, visit http://creativecommons.org/licenses/by/4.0/.

\section{References}

Burgoon JK, Buller DB (1994) Interpersonal deception: III. Effects of deceit on perceived communication and nonverbal behavior dynamics. J Nonverbal Behav 18:155-184

Cattell RB, Tsujioka B (1964) The importance of factor-trueness and validity, versus homogeneity and orthogonality, in test scales. Educ Psychol Meas 24:3-30. https://doi.org/10.1177/ 001316446402400101

Clemens F, Granhag PA, Strömwall LA (2013) Counter-interrogation strategies when anticipating questions on intentions. J Investig Psychol Offender Profiling 10:125-138. https://doi.org/10.1002/ jip. 1387

Colwell K, Hiscock-Anisman C, Memon A, Woods D, Michlik P (2006) Strategies of impression management among deceivers and truth-tellers: how liars attempt to convince. Am J Forensic Psychol 24:31-38

De Winter JCF, Dodou D, Wieringa PA (2009) Exploratory factor analysis with small sample sizes. Multivar Behav Res 44:147-181. https://doi.org/10.1080/00273170902794206

DePaulo BM, Lindsay JL, Malone BE, Muhlenbruck L, Charton K, Cooper H (2003) Cues to deception. Psychol Bull 129:74-118. https://doi.org/10.1037/0033-2909.129.1.74

Ekman P, Friesen WV (1969) Nonverbal leakage and clues to deception. Psychiatry 32:88-105. https://doi.org/10.1080/00332747.1969. 11023575

Fiske ST, \& Taylor SE (2008). Social cognition: from brains to culture. McGraw-Hill

Granhag PA, Hartwig M (2008) A new theoretical perspective on deception detection: on the psychology of instrumental mindreading. Psychol Crime Law 14:189-200. https://doi.org/10.1080/ 10683160701645181

Greene JO, O'Hair HD, Cody MJ, Yen C (1985) Planning and control of behavior during deception. Hum Commun Res 11:335-364. https:// doi.org/10.1111/j.1468-2958.1985.tb00051.x
Hair J, Anderson RE, Tatham RL, \& Black, W. C. (1995). Multivariate data analysis. 4th ed. Prentice-Hall Inc.

Hartwig M, Bond CF (2011) Why do lie-catchers fail? A lens model meta-analysis of human lie judgments. Psychol Bull 137:643-659. https://doi.org/10.1037/a0023589

Hartwig M, Granhag PA, Strömwall LA (2007) Guilty and innocent suspects' strategies during police interrogations. Psychol Crime Law 13:213-227. https://doi.org/10.1080/10683160600750264

Hartwig M, Granhag PA, Strömwall LA, Doering N (2010) Impression and information management: on the strategic self-regulation of innocent and guilty suspects. Open Criminol J 3:10-16. https://doi. org/10.2174/1874917801003010010

Knapp ML, Hart RP, Dennis HS (1974) An exploration of deception as a communication construct. Hum Commun Res 1:15-29. https://doi. org/10.1111/j.1468-2958.1974.tb00250.x

Leins DA, Fisher RF, Ross SJ (2013) Exploring liars' strategies for creating deceptive reports. Leg Criminol Psychol 18:141-151. https:// doi.org/10.1111/j.2044-8333.2011.02041.x

Lorenzo-Seva U, Timmerman ME, Kiers HAL (2011) The Hull method for selecting the number of common factors. Multivar Behav Res 46(2):340-364. https://doi.org/10.1080/00273171.2011.564527

MacCallum RC, Widaman KF, Zhang S, Hong S (1999) Sample size in factor analysis. Psychol Methods 4:84-99. https://doi.org/10.1037/ 1082-989X.4.1.84

MacCallum RC, Widaman KF, Preacher KL, Hong S (2001) Sample size and factor analysis: the role of model error. Multivar Behav Res 36: 611-637. https://doi.org/10.1207/S15327906MBR3604_06

Masip J (2013) What would you say if you were guilty?' Suspects' strategies during a hypothetical behavior analysis interview concerning a serious crime. Appl Cogn Psychol 27(1):60-70. https://doi.org/10. $1002 /$ acp. 2872

McNaughton N, \& Corr PJ (2008). The neuropsychology of fear and anxiety: A foundation for reinforcement sensitivity theory. In Corr PJ (ed.), The reinforcement sensitivity theory of personality (pp. 4494). Cambridge University Press. https://doi.org/10.1017/ CBO9780511819384.003

Mehrabian A (1971) Nonverbal betrayal of feeling. J Exp Res Pers 5: 64-73

Miller GR, \& Stiff JB (1993). Deceptive communication. Sage

Mundfrom D, Shaw D, Ke T (2005) Minimum sample size recommendations for conducting factor analyses. Int J Test 5(2):159-168. https://doi.org/10.1207/s15327574ijt0502_4

Nisbett, R. E., \& Ross, L. (1980). Human inference: strategies and shortcomings of social judgment. Prentice Hall

Nisbett RE, Wilson TD (1977) Telling more than we can know: verbal reports on mental processes. Psychol Rev 84:231-259. https://doi. org/10.1037/0033-295X.84.3.231

Olsson U (1979) Maximum likelihood estimation of the polychoric correlation coefficient. Psychometrika 44:443-460. https://doi.org/10. 1007/BF02296207

Peterson RA (2000) A meta-analysis of variance accounted for and factor loadings in exploratory factor analysis. Mark Lett 11:261-275. https://doi.org/10.1023/A:1008191211004

Sporer SL, Schwandt B (2006) Paraverbal indicators of deception: a meta-analytic synthesis. Appl Cogn Psychol 20:421-446. https:// doi.org/10.1002/acp.1190

Sporer SL, Schwandt B (2007) Moderators of nonverbal indicators of deception: a meta-analytic synthesis. Psychol Public Policy Law 13:1-34. https://doi.org/10.1037/1076-8971.13.1.1

Strömwall LA, Willén RM (2011) Inside criminal minds: Offenders' strategies when lying. J Investig Psychol Offender Profiling 8:271-281. https://doi.org/10.1002/jip.148

Strömwall LA, Hartwig M, Granhag PA (2006) To act truthfully: nonverbal behavior and strategies during a police interrogation. Psychol Crime Law 12:207-219. https://doi.org/10.1080/ 10683160512331331328 
Tabachnick BG, \& Fidell LS (2001). Using multivariate statistics. Allyn and Bacon

Timmerman ME, Lorenzo-Seva U (2011) Dimensionality assessment of ordered polytomous items with parallel analysis. Psychol Methods 16:209-220. https://doi.org/10.1037/a0023353

Velicer WF (1976) Determining the number of components from the matrix of partial correlations. Psychometrika 41(3):321-327. https://doi.org/10.1007/BF02293557

von Hippel W, Trivers R (2011) The evolution and psychology of selfdeception. Behav Brain Sci 34:1-16. https://doi.org/10.1017/ S0140525X10001354

Vrij A (2010) Detecting lies and deceit: pitfalls and opportunities. Wiley

Vrij A, Granhag PA (2012) Eliciting cues to deception and truth: what matters are the questions asked. J Appl Res Memory Cognit 1:110 117. https://doi.org/10.1016/j.jarmac.2012.02.004

Vrij A, Semin GR, Bull R (1996) Insight into behavior during deception. Hum Commun Res 22:544-562. https://doi.org/10.1111/j.14682958.1996.tb00378.x

Vrij A, Akehurst L, Morris PM (1997) Individual differences in hand movements during deception. J Nonverbal Behav 21:87-102. https://doi.org/10.1023/A:1024951902752
Vrij A, Fisher R, Mann S, Leal S (2008) A cognitive load approach to lie detection. J Investig Psychol Offender Profiling 5:39-43. https://doi. org/10.1002/jip. 82

Vrij A, Mann S, Leal S, Granhag P (2010) Getting into the minds of pairs of liars and truth tellers: an examination of their strategies. Open Criminol J 3(1):17-22. https://doi.org/10.2174/ 18749178010030200017

Vytal K, Cornwell B, Arkin N, Grillon C (2012) Describing the interplay between anxiety and cognition: from impaired performance under low cognitive load to reduced anxiety under high load. Psychophysiology 49:842-852. https://doi.org/10.1111/j.14698986.2012.01358.x

Zuckerman M, DePaulo BM, Rosenthal R (1981) Verbal and non-verbal communication of deception. Adv Exp Soc Psychol 14:1-57. https://doi.org/10.1016/S0065-2601(08)60369-X

Publisher's Note Springer Nature remains neutral with regard to jurisdictional claims in published maps and institutional affiliations. 